\title{
Penerapan Case Based Reasoning (Cbr) Pada Sistem Pakar Diagnosa Penyakit Otitis Media Supuratif Kronis (Omsk) Pada Orang Dewasa
}

\author{
Gita Triswardani ${ }^{1}$, Nelly Astuti Hasibuan² \\ ${ }^{1}$ Mahasiswa Program Studi Teknik Informatika, STMIK Budi Darma, Medan, Indonesia \\ ${ }^{2}$ STMIK Budi Darma, Medan, Indonesia
}

\begin{abstract}
Abstrak
Otitis Media Supuratif Kronis (OMSK) adalah infeksi peradangan mukosa telinga tengah dengan perforasi membrane timfani dan secret yang keluar dari telinga secara terus menerus, dahulu disebut otitis media perforate (OMP) dalam sebutan seharihari congek. Otitis media supuratif kronis (OMSK) biasa ditemukan pada masyarakat kelas menengah ke bawah, dan menyebabkan meningkatnya biaya untuk pengobatan. Oleh karena itu diperlukan suatu alat atau sistem yang memiliki kemampuan layaknya seorang dokter dalam mendiagnosa penyaki. tSistem pakar digunakan bukan untuk menggantikan fungsi dokter, akann tetapi hanya digunakan sebagai pelengkap suatu sistem dan alat bantu. Sistem pakar adalah sistem yang mampu menirukan penalaran seorang pakar komputer dapat menyelesaikan masalah yang seperti biasa dilakukan oleh para ahli. Metode yang digunakan pada sistem pakar ini menggunakan metode case based reasoning(CBR), karena metode ini menghasilkan nilai kmiripan suatu kasus dengan kasus terdahhulu dengan mengingat kejadian-kejadian yang sama (similar)yang pernah terjadi di masa lalu kemudian menggunakan pengetahuan atau informasi tersebut untuk menyelesaikan masalah yang baru, atau dengan kata lain menyelesaikan masalah dengan mengadopsi solusi-solusi yang pernah digunakan di masa lalu.
\end{abstract}

Kata Kunci: Otitis Media Supuratif Kronis, Sistem Pakar, Case Based Reasoning

\section{Abstract}

Chronic Suppurative Otitis Media (OMSK) is an infection of middle ear mucosal inflammation with perforated tympanic membrane and secret from the ear continuously, formerly called otitis media perforate (OMP) in everyday congek. Chronic suppurative otitis media (OMSK) is commonly found in lower middle-class people, and leads to increased costs for treatment. Therefore required a tool or system that has the ability of a doctor in diagnosing the disease. The expert system is used not to replace the physician's function but will be used only as a complement to a system and aids. An expert system is a system capable of mimicking the reasoning of a computer expert to solve problems as is usually done by experts. The method used in this expert system uses case-based reasoning (CBR) method, since this method yields the value of kmiripan a case with the former by recalling similar events that have occurred in the past then use the knowledge or information to solve a new problem, or in other words solve the problem by adopting solutions that have been used in the past.

Keywords: Chronic Suppurative Otitis Media, Expert System, Case Based Reasoning

\section{PENDAHULUAN}

Penyakit otitis media supuratif kronis merupakan penyakit pada telinga dibagian tengah yang dialami bila lebih dari 2 bulan yang ditandai dengan keluarnya cairan pada telinga. Biasanya penyakit ini dalam sehari-hari sering disebut dengan penyakit congek.

Permasalahan yang sering terjadi pada masyarakat adalah ketersediaan pakar yang memiliki pengetahuan tertentu, seperti dokter spesialis THT, yang tidak mudah diperoleh ataupun waktunya yang terbatas, ataupun terkendala dengan kurangnya biaya bagi masyarakat yang ingin berobat ataupun bertemu dengan pakar. Sehingga para pasien yang menderita penyakit ini perlu penanganan yang segera. Oleh karena itu perlu dibangun suatu sistem yang dapat membantu penderita, dokter atau siapapun yang bergerak dibidangnya untuk dapat meringankan pekerjaannya. Sistem tersebut adalah sistem pakar, sistem pakar adalah sistem yang mampu menirukan penalaran seorang pakar kedalam komputer sehingga dapat menyelesaikan masalah yang seperti biasa dilakukan oleh para ahli.

Metode case based reasoning $(C B R)$ merupakan sistem penalaran berbasis kasus yang menggunakan pengalaman atau kasus terdahulu sehingga dapat menyelesaikan masalah atau kasus yang baru. Ada beberapa tahapan pada metode case based reasoning, diantaranya retrieve, reuse, revise, dan retain.

Seperti yang terlihat pada penelitian sebelumnya dalam jurnal Faza Akmal dan Sri Winiarti,2014 dengan judul "Sistem pakar Mendiagnosa Penyakit Lambung Dengan Implementasi Metode Case Based Reasoning (CBR) Berbasis Web" yaitu dalam mendiagnosa penyakit lambung dengan menggunakan metode Case Based Reasoning untuk mencari nilai kemiripan penyakit dengan kasus terdahulu dan metode Certainty Factor digunakan untuk mencari nilai kepastian penyakit dengan menghitung nilai probabilitas gejala pada penyakit [1]. 


\section{TEORITIS}

\subsection{Sistem Pakar}

Sistem pakar merupakan cabang dari Artificial Intelligence (AI) yang cukup tua karena sistem ini mulai dikembangkan pada pertengahan 1960. Sistem pakar yang muncul pertama kali adalah General-purpose problem solver (GPS) yang dikembangkan oleh Newel dan Simon. Sampai saat ini sudah banyak sistem pakar dibuat, seperti MYCIN untuk diagnosis penyakit, DENDRAL untuk mengidentifikasi struktur molekul campuran yang tak dikenal, XCON \& XSEL untuk membantuk konfigurasi sistem komputer besar, SOPHIE untuk analisis sirkuit elektronik, prospector digunakan di bidang geologi untuk membantu mencari dan menemukan deposit, FOLIO digunakan untuk membantu memberikan keputusan bagi seorang manager dalam stok dan investasi, DELTA dipakai untuk pemeliharaan lokomotif listrik diesel dan sebagainya [2].

Sistem pakar adalah sebuah sistem yang menggunakan pengetahuan manusia yang dimasukkan kedalam sebuah komputer dimana komputer akan merepresentasikan dan melakukan penalaran dengan beberapa pengetahuan pakar

\subsection{Penyakit Otitis Media Supuratif Kronis (OMSK)}

Penyakit Otitis Media Supuratif Kronis (OMSK) adalah infeksi kronis di telinga tengah lebih dari 2 bulan dengan adanya perforasi membrane timpani, sekret yang keluar dari telinga tengah terus menerus atau hilang timbul. Sekret bisa encer atau kental, bening atau nanah. Otitis media supuratif kronis dahulu disebut otitis media perforate (OMP) atau dalam sebutan sehari-hari congek [5].

Gejala yang ditimbulkan yaitu diantaranya daya tahan tubuh pasien melemah, telinga berair, pendengaran menurun, telinga terasa nyeri, tellinga berdenging, telinga berdarah, nyeri kepala, telinga tersumbat.

\subsection{Metode Case Based Reasoning (CBR)}

Case Based Reasoning (CBR) merupakan sistem yang bertujuan untuk menyelesaikan suatu kasus baru dengan cara mengadaptasi solusi-solusi yang terdapat kasus-kasus sebelumnya yang mirip dengan kasus baru tersebut[6].

Metode CBR melakukan empat tahapan proses di dalam sistem penalaran basis kasus, pertama melakukan proses retrieve yaitu penelusuran kasus yang paling mirip dengan kasus baru yangakan dievaluasi, kemudian melakukan proses yang kedua reuse yaitu menggunakan kembali informasi atau pengetahuan yang telah tersimpan pada basis kasus untuk memecahkan masalah baru, ketiga melakukan proses revise yaitu memperbaiki solusi yang diusulkan, dan terakhir melakukan proses retain, yaitu menyimpan pengetahuan yang nantinya akan digunakan untuk memecahkan masalah kedalam basis kasus yang ada. Metode CBR digunakan untuk mencari nilai kemiripan penyakit dengan kasus terdalulu, sedangkan untuk mencari nilai kepastian atau nilai keyakinan penyakit digunakan metode certainty factor. Metode certainty factor (CF) merupakan metode yang mendefinisikan ukuran kepastian terhadap suatu fakta atau aturan, untuk mengambarkan tingkat keyakinan pakar terhadap masalah yang sedang dihadapi, dengan menggunakan certainty factor ini dapat mengambarkan tingkat keyakinan pakar. Berikut adalah rumus untuk mencari nilai kemiripan (similiarity) :

$$
\mathrm{Ti}=\frac{\mathrm{nX} 1+\mathrm{nX} 2+\mathrm{nX} 3}{\mathrm{~N}}
$$

Keterangan :

$\mathrm{Ti}$

$\mathrm{nX} 1+\mathrm{nX} 2+\mathrm{nX} 3$

$\mathrm{N}$

$$
\begin{aligned}
& =\text { Nilai kesamaan kasus } \\
& =\text { Banyak kesamaan subobjek X1, X2, X3 .......Xn } \\
& =\text { Banyak elemen pada basis kasus }
\end{aligned}
$$

Berikut merupakan rumus untuk mencari nilai kepastian [1]:

$\mathrm{CF}(\mathrm{h}, \mathrm{e})=\mathrm{MB}(\mathrm{h}, \mathrm{e})-\mathrm{MD}(\mathrm{h}, \mathrm{e})$

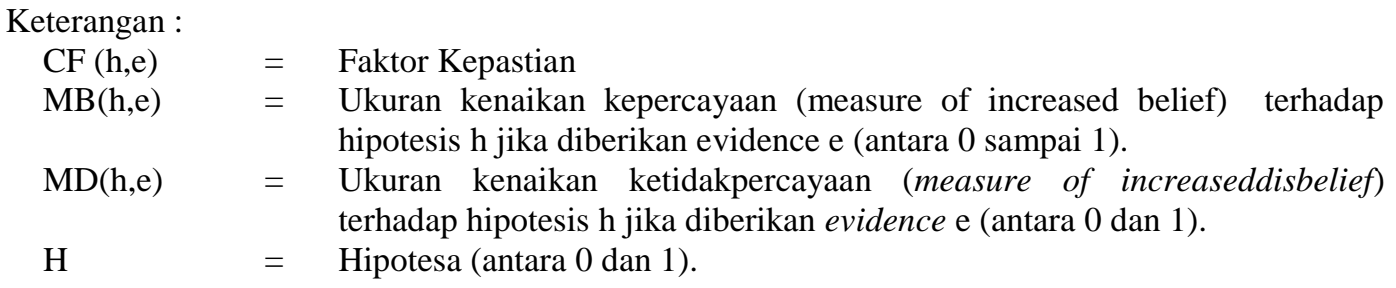


$\mathrm{E} \quad=\quad$ Peristiwa atau fakta (evidence) .

Beberapa evidence dikombinasikan untuk menentukana CF dari suatu hipotesis. Jika e1 dan e2 adalah observasi, maka :

$\mathrm{MB}[\mathrm{h}, \mathrm{e} 1 \wedge \mathrm{e} 2]=\{\mathrm{MB}[\mathrm{h}, \mathrm{e} 1]+\mathrm{MB}[\mathrm{h}, \mathrm{e} 2] \cdot[1-\mathrm{MB}[\mathrm{h}, \mathrm{e} 1]\}$

$\mathrm{MB}[\mathrm{h}, \mathrm{e} 1 \wedge \mathrm{e} 2]=\{\mathrm{MD}[\mathrm{h}, \mathrm{e} 1]+\mathrm{MD}[\mathrm{h}, \mathrm{e} 2] .[1-\mathrm{MD}[\mathrm{h}, \mathrm{e} 1]\}$

\section{ANALISA DAN PEMBAHASAN}

Analisa sistem merupakan suatu tahapan untuk membantu memahami sesuatu yang dibutuhkan sistem dan mempelajari permasalahan-permasalahan yang ada untuk kemudian dilakukannya solusi penyelesaian yang didasarkan pada kebutuhan pengguna sistem agar tercipta sebuah sistem yang berguna bagi pengguna. Sehingga nantinya dapat membantu didalam proses perancangan model suatu sistem yang akan diimplementasikan.

Penyakit Otitis Media Supuratif Kronis (OMSK) adalah infeksi kronis di telinga tengah lebih dari 2 bulan dengan adanya perforasi membrane timpani, sekret yang keluar dari telinga tengah terus menerus atau hilang timbul. Sekret bisa encer atau kental, bening atau nanah. Sangat disayangkan jika penyakit ini meningkat kejadiannya dari waktu ke waktu hanya karena ketidaktahuan masyarakat awam, sehingga mereka tidak siap siaga menghadapi ancaman penyakit yang setiap saat ada dihadapan kita.

Case-Based Reasoning (CBR) merupakan sistem yang bertujuan untuk menyelesaikan suatu kasus baru dengan cara mengadaptasi solusi-solusi yang terdapat pada kasus-kasus sebelumnya yang mirip dengan kasuskasus sebelumnya. Kemiripan (Similarity) merupakan langkah yang digunakan untuk mengenali kesamaan atau kemiripan antara kasus-kasus yang tersimpan dalam basis kasus dengan kasus yang baru. Kasus yang dengan nilai similarity paling besar dianggap sebagai kasus yang paling mirip, nilai similarity berkisar antara 0 dan 1 . Sedangkan metode Certainty factor digunakan untuk mencari nilai kepastian penyakit dengan menghitung nilai probabilitas gejala pada penyakit.

Tabel 1. Gejala Penyakit Otitis Media Supuratif Kronis

\begin{tabular}{|c|c|c|}
\hline Kode Gejala & Nama Gejala & Bobot Kepastian \\
\hline G01 & $\begin{array}{c}\text { Daya Tahan Tubuh Pasien } \\
\text { Rendah }\end{array}$ & 0,4 \\
\hline G02 & Telinga berair & 0,8 \\
\hline G03 & Pendengaran menurun & 0,8 \\
\hline G04 & Telinga nyeri & 0,8 \\
\hline G05 & Telinga berdenging & 0,8 \\
\hline G06 & Telinga berdarah & 0,6 \\
\hline G07 & Nyeri Kepala/ Vertigo & 0,6 \\
\hline G08 & Telinga Tersumbat & 0,8 \\
\hline
\end{tabular}

Dalam mengekspresikan derajat kepastian, untuk mengasumsikan derajat kepastian seorang pakar terhadap suatu data. Konsep ini kemudian diformulasikan dalam rumus-rumus dasar. Menerapkan sistem penalaran Case Based Reasoning (CBR) dan metode Certainty Factor (CF) dalam mendiagnosa penyakit otitis media supuratif kronis, yaitu sebagai berikut :

Contoh kasus pertama pada pasien pertama $(\mathrm{Pa} 1)$ dapat dilihat pada tabel berikut :

Tabel 2. Input Gejala Kasus Baru

\begin{tabular}{|l|l|}
\hline Inputan Konsultasi & Gejala Yang Dinputkan \\
\hline
\end{tabular}




\begin{tabular}{|l|l|}
\hline 1 & G01, G02, G04 \\
\hline
\end{tabular}

Tabel 3. Kasus Baru Yang Mirip Terdahulu

\begin{tabular}{|c|c|}
\hline Keterangan & Gejala \\
\hline Otitis media supuratif kronis & G01, G02, G03, G04, G05, G06, G07, G08 \\
\hline Kasus Baru & G01, G02,G04 \\
\hline
\end{tabular}

Pada tabel 4 merupakan tabel perbandingan gejala penyakit, nilai MB (ukuran kenaikan kepercayaan) dan MD (ukuran kenaikan ketidakpercayaan) didapat dari perhitungan pada tabel 3.4, dimana nilai MB diperoleh dengan cara menghitung banyaknya kasus pada gejala pertama dibagi dengan jumlah pasien, sedangkan nilai MD diperoleh dengan cara menghitung 1 dikurang dengan MB yaitu sebagai berikut :

1. $\mathrm{MB} \mathrm{G} 01=\underline{\text { Banyaknya kasus pada } \mathrm{G} 01}$

$$
\begin{aligned}
& =\frac{20}{30}=0,66 \\
\text { MD G01 } & =1-\mathrm{MB} \\
& =1-0,66 \\
& =0,34
\end{aligned}
$$

Pada sesi penginputan sistem, user diberi jawaban yang masing-masing memiliki bobot sebagai berikut:

\begin{tabular}{|c|c|c|c|c|}
\hline \multicolumn{2}{|c|}{ Otitis Media Supuratif Kronis } & \multirow{2}{*}{$\begin{array}{l}\text { Similiarity } \\
\text { coefficient }\end{array}$} & \multirow[t]{2}{*}{$\mathrm{MB}$} & \multirow[t]{2}{*}{$\mathrm{MD}$} \\
\hline $\begin{array}{c}\text { Kode Gejala Kasus } \\
\text { Lama } \\
\end{array}$ & $\begin{array}{c}\text { Kode Gejala Kasus } \\
\text { baru }\end{array}$ & & & \\
\hline G01 & G01 & 1 & 0.66 & 0.34 \\
\hline G02 & G02 & 1 & 0.6 & 0.4 \\
\hline G03 & 0 & 0 & 0.66 & 0.34 \\
\hline G04 & G04 & 1 & 0.33 & 0.67 \\
\hline G05 & 0 & 0 & 0.43 & 0.57 \\
\hline G06 & 0 & 0 & 0.1 & 0.9 \\
\hline G07 & 0 & 0 & 0.86 & 0.14 \\
\hline G08 & 0 & 0 & 0.1 & 0.9 \\
\hline
\end{tabular}
Pilihan jawaban "Ya" $=1$

Pilihan jawaban "Tidak" $=0$

Tabel 4 Perbandingan Gejala Penyakit

Dalam menghitung nilai kemiripan kasus terdahulu dengan kasus baru di formulasikan dengan menghitung nilai kemiripan, yaitu sebagai berikut:

1. Perhitungan Nilai Kemiripan (Similiarity)

$$
\begin{aligned}
& T i=\frac{\mathrm{n} . \mathrm{X} 1+\mathrm{n} . \mathrm{X} 2+\mathrm{n} . \mathrm{X} 3+\mathrm{n} . \mathrm{Xn}}{\mathrm{N}} \\
& =\frac{[(1 * 0.66)+(1 * 0.6)+(1 * 0.33)]}{(0.66+0.6+0.66+0.33+0.43+0.1+0.86+0.1)} \\
& =\frac{1.59}{3.74}=0.4251 * 100 \\
& =42.51 \%
\end{aligned}
$$


2. Menghitung Nilai Kepastian (Certainty Factor)

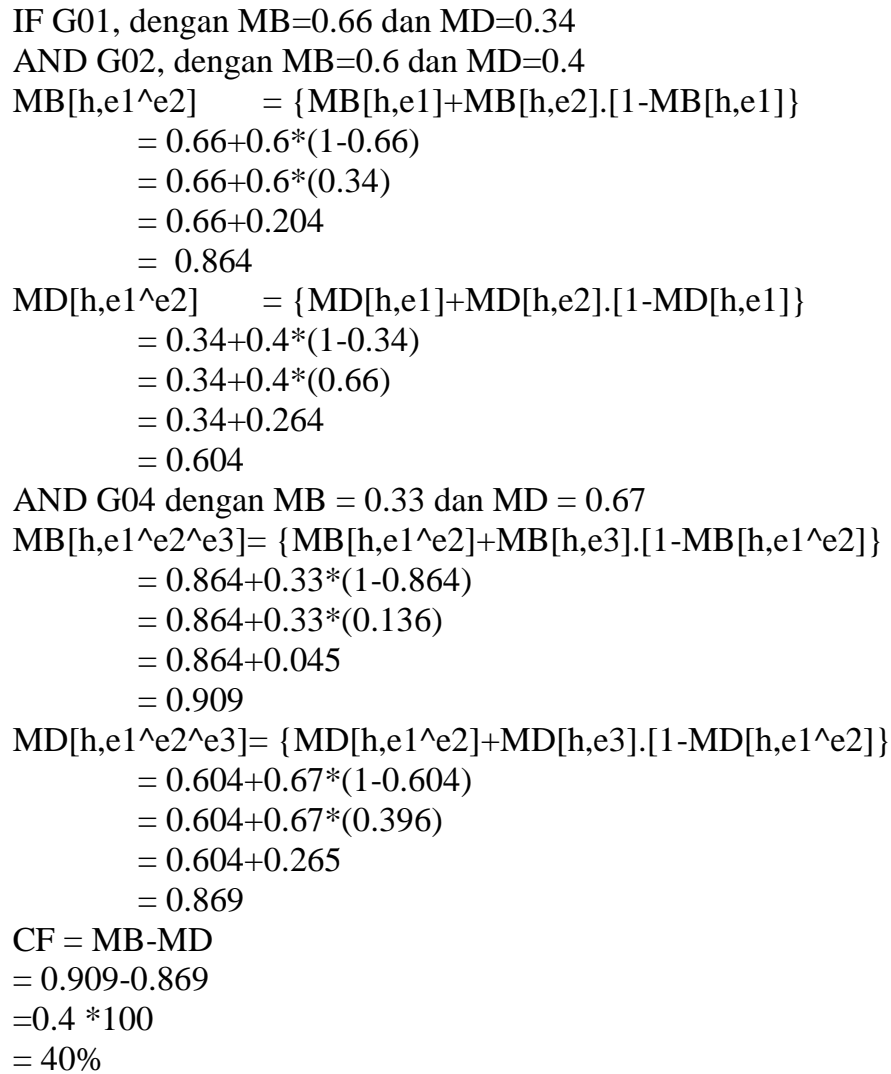

Dengan demikian dapat dikatakan bahwa terdapat kemiripan pada kasus terdahulu dengan nilai $42.51 \%$ dan perhitungan nilai CF mendiagnosa penyakit otitis media supuratif kronis memiliki persentase tingkat keyakinan $40 \%$

\section{KESIMPULAN}

Berdasarkan pembahasan yang dilakukan pada skripsi ini, maka diperoleh beberapa kesimpulan, antara lain:

1. Penyakit otitis media supuratif kronis dapat di diagnose dengan system pakar dengan cara menerjemahkan atau merepresentasikan gejala penyakitnya kedalam rule.

2. Metode case based reasoning dapat diterapkan untuk melihat kemiripan nilai suatu penyakit terhadap kasus sebelumnya.

3. Sistem pakar mendiagnosa penyakit otitis media supuratif kronis dirancang dengan Microsoft Visual Basic.Net 2008 dan database MySql.

\section{REFERENCES}

[1] F. Akmal dan S. Winiarti, "SISTEM PPAKAR UNTUK MENDIAGNOSA PENYAKIT LAMBUNG DENGAN IMPLEMENTASI METODE CBR (CASE BASED REASONING) BERBASIS WEB," Jurnal Sarjana Teknik Informatika, Vol. 2, No. 1, Februari 2014.

[2] E. Mulyanto. V. Suhartono. T.Sutojo, Kecerdasan Buatan, Yogyakarta: Andi, 2011.

[3] R. Rosnelly, Sistem Pakar Konsep dan Teori, Yogyakarta: Andi, 2012.

[4] Depdiknas, Kamus Besar Bahasa Indonesia Edisi ketiga, Jakarta: Balai Pustaka, 2007.

[5] R. D. Restuti. et all, Telinga Hidung Tenggorok Kepala dan Leher edisi ketujuh, Jakarta: FK UI, 2012.

[6] Adriana. Indarto. Abdiansah, Penalaran Komputer Berbasis Kasus (Case Based Reasoning), Yogyakarta: Ardana Media, 2007.

[7] Y. Sugiarti, Analisa dan Perancangan UML, Yogyakarta: Graha Ilmu, 2013.

[8] K. Darmayuda, Pemrograman Aplikasi Database Dengan Microsoft Visual Basic.Net 2008, Bandung: Informatika, 2010.

[9] W. Komputer, Shortcourse SQL Server 2008 Express, Semarang: Andi, 2010. 
[10] P. A. S. (PAS), Membuat Aplikasi Client Server Dengan Visual Basic 2008, Yogyakarta: ANDI, 2010.

[11] B. Nugroho, Panduan Lengkap Menguasai Perintah SQL, Jakarta: Media Kita, 2008.

[12] N. A. Hasibuan, K. Yusmiarti, F. T. Waruwu, and R. Rahim, "Expert systems with genetics probability," Int. J. Res. Sci. Eng., vol. 3 , no. 2, pp. 112-116, 2017.

[13] I. Sumatorno, D. Arisandi, A. P. U. Siahaan, and Mesran, "Expert System of Catfish Disease Determinants Using Certainty Factor Method," Int. J. Recent Trends Eng. Res., vol. 3, no. 8, pp. 202-209, 2017.

[14] R. R. Fanny, N. A. Hasibuan, and E. Buulolo, "PERANCANGAN SISTEM PAKAR DIAGNOSA PENYAKIT ASIDOSIS TUBULUS RENALIS MENGGUNAKAN METODE CERTAINTY FACTOR DENGAN PENULUSURAN FORWARD CHAINING," MEDIA Inform. BUDIDARMA, vol. 1, no. 1, Feb. 2017.

[15] R. P. Tanjung and Mesran, "SISTEM PAKAR MENDETEKSI KERUSAKAN MESIN LAS INVERTER DENGAN METODE CERTAINTY FACTOR,” Maj. Ilm. INFOTEK, vol. 2, no. 1, pp. 62-64, 2017.

[16] Yeni Lestari Nasution, M. Mesran, S. Suginam, and F. Fadlina, "SISTEM PAKAR UNTUK MENDIAGNOSIS PENYAKIT TUMOR OTAK MENGGUNAKAN METODE CERTAINTY FACTOR (CF),”J. INFOTEK, vol. 2, no. 1, Feb. 2017.

[17] Verawaty Monica Barus, M. Mesran, S. Suginam, and A. Karim, "SISTEM PAKAR UNTUK MENDIAGNOSIS HAMA PADA TANAMAN JAMBU BIJI MENGGUNAKAN METODE BAYES,”J. INFOTEK, vol. 2, no. 1, Feb. 2017. 